\title{
MULTIPLE PROGRESSION - A PROPOSED NEW SYSTEM FOR THE APPLICATION OF QUALITY FUNCTION DEPLOYMENT IN THE PROCESS INDUSTRY
}

\author{
THOMAS LAGER \\ Centre for Management of Innovation and Technology in Process Industry \\ Luleå University of Technology, SE-97187 Luleå, Sweden \\ thomas.lager@ltu.se
}

Received 27 December 2003

Revised 31 October 2004

Accepted 2 November 2004

\begin{abstract}
After a thorough literature review of the present Quality Function Deployment (QFD) methodology and its use in the process industry, it has been concluded that present QFD systems do not address the specific needs of this type of industry. A new QFD system has consequently been developed based on those research findings. The new system has been specially adapted to Process Industry applications and production systems that are often characterised by long chains of customers and suppliers and sometimes by lack of direct contact with end users. The use of the new system is illustrated by a simplified industrial case, and its further application in Process Industry is discussed.
\end{abstract}

Keywords: Multiple progression; quality function deployment (QFD); process industry.

\section{Introduction}

In the management of $R \& D$, methodologies and other tools to facilitate and improve the performance of various $R \& D$ activities come and go. Sometimes methodologies vanish and finally disappear because they were not good enough to stand the tough industrial environment and its high demands on industrial usability. Sometimes methodologies have been introduced in companies with good results, but did not get further attention or a "company champion" to keep them alive when new promising tools emerge and are promoted by company R\&D management. Because of this, there is always a need not only to evaluate the usability of R\&D methodologies but also to develop them further in order to make them more useful in industrial applications. This assessment of methodologies and their further development ought to go hand in hand, and this is an area of responsibility for academic scholars. The 
company introduction and facilitation can, on the other hand, rest with management consultants.

This research project was started out of a growing concern on the author's part that the potential of Quality Function Deployment (QFD) methodology was not fully realised in its application in the process industry. The project was thus initiated partly because of the author's own dissatisfaction with the methodology after participating in the introduction and use of QFD in some large projects in the process industry, partly because publications from applications in the process industry appeared to be becoming more rare. One could not unreasonably speculate that the sparse reporting of the use of QFD in the process industry, and more specifically its use beyond the initial "House of Quality", could be attributed not only to lack of resources and time of the company, but possibly also to lack of methodological guidance in reference literature. The lack of a user-friendly QFD system specially adapted for use in the process industry could also be one contributing factor to this circumstance.

The purpose of this research project was thus to review and possibly improve the QFD methodology for its application and use in the process industry. Two research questions arose: first of all to assess the methodology in its process industry application and secondly to utilise this body of knowledge in a search for possible ways to improve the methodology and its use, mainly in product and process development. The work consequently started with an analysis of existing QFD systems. The author had long previous experience of using the modified ASI system "Four Phases of Matrices" (American Supplier Institute, 1989) in the process industry, and during a visit to Japan in 2002 studied the original "Matrix of Matrices" developed by Akao (1990).

After a thorough review and analysis of relevant publications related to the process industry, it was decided to develop a new QFD system especially adapted for process industry applications. The new system was then gradually developed during 2003 and is presented here as a system with its integral components (matrices) and rooms. The proposed new system was then illustrated with the development of an industry-related case from the beverage industry. The aim of this paper is thus not to discuss the implementation of the proposed new system and the use of individual rooms in detail, but to present a new structural framework for QFD applications in the process industry, which was one of the final results from this research project.

The contents of this paper can be separated into two main parts. The first part is a short presentation of currently used QFD systems in industry followed by a thorough review of published literature on process industry application. The analysis and synthesis of those findings form the point of departure for the second part, which is the theoretical development of the new QFD system especially adapted for process industry applications. This part also includes the explanatory industrial case to improve understanding of the new system. Finally, the results are discussed and conclusions are drawn. But before we go into the presentation of QFD methodology 
and its use in the process industry, we may first reflect upon the differences between the process industry and other manufacturing industries that may influence the necessity to develop and use a special QFD system.

\section{A comparison of the process industry and other manufacturing industries}

There are certainly a number of similarities between the process industry and other types of manufacturing industry, but there are also a number of differences. In the following presentation the focus is on differences that particularly influence the application and the usability of QFD methodology in the process industry. The following definition by Lager, which characterises this industry in a descriptive manner, has been used in this study (Lager, 2000, p. 322):

\section{"Process Industry is Production Industry using (raw) materials to manufacture non-assembled products in a production process where the (raw) materials are processed in a production plant where different unit operations often take place in a fluid form and the dif- ferent processes are connected in a continuous flow".}

This definition covers a large number of industrial sectors such as mineral and metal industry, forest industry, food and beverage industry, chemical and petrochemical industry, etc.

\section{The complex production chain}

One characteristic feature of significant importance to product and process development in the process industry is the complex production chain illustrated in Fig. 1. The production chain, starting with raw materials, often includes intermediate deliveries of other finished products before final production and delivery of the finished product to the customer. The production chain may include a number of large or small production plants, sometimes operated and owned by different companies or sometimes fully integrated in a long production chain within an industrial group or conglomerate (Lager, 2002).

The often long and complex chain structure of production units and interfaces as in Fig. 1 can sometimes create artificial obstacles, preventing sound product and process development and disconnecting the total chain of customer demands on the products. Successful development of new products and new processes depends to a high degree on an understanding of this total chain structure (Tottie and Lager, 1995). On the other hand, the internal production chain with no formal supplier/customer interfaces may be too diffuse to clearly define the internal demands and needs regarding the intermediate products, with the result that the internal chain is suboptimised because of internal discussions and disputes. 


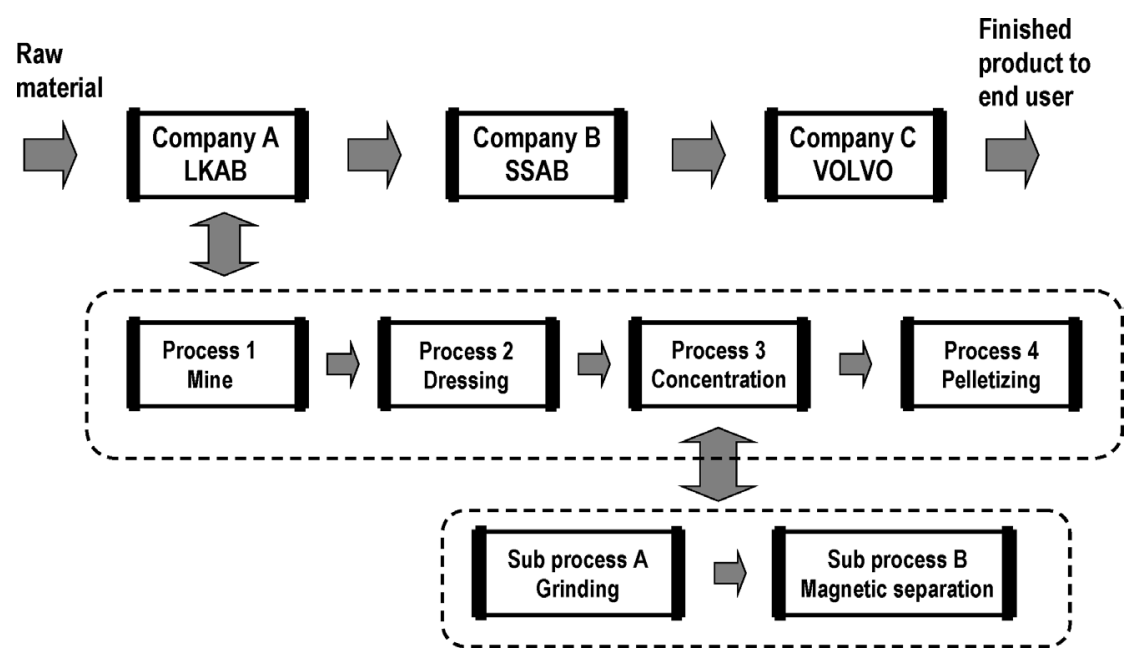

Fig. 1. A schematic model of a production chain in the process industry. A production chain in the process industry is sometimes even more complex than in other manufacturing industries. The top line shows the production chain on a company level from raw material to end user. The middle line shows the production chain within one company, where the structure often reflects the plant interfaces. The bottom line represents the sub-process level, sometimes on such a detailed level as "unit operation".

\section{Sometimes the customer is not the end user}

The complex production and supply chain presented in Fig. 1 is not unusual in the process industry. In Fig. 1, LKAB (a mining company) supplies advanced iron ore pellets to SSAB (a steel mill company), which in turn delivers rolled sheet steel to the car manufacturer Volvo. LKAB is thus far removed from the end user, who is the consumer who opts to buy a car from Volvo. The customer's demands on a Volvo car are presumably cascaded backwards in this supply chain, ultimately making stringent demands on the iron ore raw material that is mined and refined at the LKAB production plants. It can also be noted that Volvo is a manufacturing company and thus falls outside the process industry category. The consequence is that Volvo can use the conventional QFD systems that are suitable for companies that assemble components. When Volvo sets the specifications for components that are manufactured from sheet steel, those specifications start the progression of raw material properties to the supplier in the process industry.

\section{Homogeneous outgoing products and product and process development often go hand in hand}

The output from the process industry is most often "non-assembled" products. The finished product is thus more or less homogeneous, but can have an inner structural complexity going from total homogeneity, e.g., sulphuric acid, to a product with 
a more complex and designed inner structure such as advanced paperboard for packaging. There are a number of similarities between the process industry and other manufacturing industries with regard to development activities and how they are performed, but also a number of differences. The main difference is probably the strong relation between product development and process development. The product is thus not developed in a design office but in the laboratory. In the further development processes, going from bench testing, a prototype is not developed but test quantities are often produced in pilot plants or in small batches in production plants. An understanding of the production process is thus vital to the development of new products.

\section{Quality Function Deployment in the Process Industry}

\section{An introduction to present QFD systems, matrices (components) and rooms}

\section{A brief QFD history and background}

The methodology originated in Japan, where quality work had been carried out from the beginning of the 1950s. One important person in this quality movement at the end of the 1960s was Professor Akao, who is considered as one spiritual father of QFD methodology. It had its breakthrough in Japanese manufacturing industry, and is often ascribed to Toyota Auto Body, whose use of QFD successfully contributed to solving their problems with rusting cars. The methodology was initially called Quality Deployment until, at the beginning of the 1970s, the product matrix was introduced at Mitsubishi Heavy Industries' Kobe Shipyard. Professor Furukawa assisted in its use and further development of the methodology, and also acted as an important link in transferring it to the United States at the beginning of the 1980s.

The first and original system, developed by Professor Akao (1990), is still the dominant system used in Japan. It was introduced in a slightly modified form by GOAL/QPC (King, 1987). The system includes a large number of matrices and is often referred to as the "Matrix of Matrices". A simplified version, developed by Dr Fukuhara, received wide publicity when it was presented in the Harvard Business Review under the designation "House of Quality", while the ladder of four consecutive matrices is often referred to as the "Four Phases of Matrices" (Hauser and Clausing, 1988). The QFD methodology was first applied in America in the automotive industry, where it was successfully introduced by the American Supplier Institute (ASI) (American Supplier Institute, 1989) and GOAL/QPC. Those two matrix structures represent the two different QFD systems that are in practical use worldwide today. The methodology was then further disseminated worldwide and introduced in Europe at the end of the 1980s. 


\section{A short presentation of QFD systems and matrices (components)}

QFD methodology is unfortunately often presented in a rather superficial manner using simplified descriptions of the House of Quality and finishing with a presentation of how customer demands have progressed to production planning using four consecutive matrices. The methodological reality is however more complex, since there are first of all two different systems in use today. Looking into the industrial use of the methodology, one finds that very few companies have ever tried the phase progression into deeper levels and used the methodology to its full extent (Cristiano et al., 2000; Martins and Aspinwall, 2001). In the process industry, the four-stage progression system is not even applicable, because the products are not assembled components. In further discussion of QFD methodology there is first of all a need to select a common language with clearly defined terms. In this study, the following definition from system theory has been used: "A system can be defined as a set or assemblage of entities (elements or components) interrelated to each other and to the whole so as to achieve a common goal" (Neelamkavil, 1987). In this presentation, the various matrices are thus also called "components" and the total set of matrices, "QFD systems". This terminology emphasises the interrelationship between the respective matrices, but also reflects the classical picture from system theory of information input, the transformation concept for the total system and for individual components, and the final output from components and systems which is also achieved by the QFD methodology and individual matrices. The individual parts of the matrices are traditionally designated "rooms". This study focuses on the QFD systems and their components (matrices), and the use of the individual rooms is therefore treated in less detail. In all systems there is one common component (matrix) where everything starts. This component is nowadays often called the "House of Quality".

\section{House of Quality or the Product Planning Matrix — the common component of all systems}

The translation of "Customer Demands" into "Product Properties" takes place in the House of Quality in both the Matrix of Matrices and Four Phases of Matrices systems. The terminology varies from one source to another: the WHATs and the HOWs that are called "Customer Demands" and "Product Properties" in this paper are called "Demanded Quality" and "Quality Characteristics" by Akao (1990). ASI calls them "Customer Wants" and "Design Requirements" (American Supplier Institute, 1989), and Hauser and Clausing (1988) call them "Customer Attributes" and "Engineering Characteristics". We will not go into a detailed presentation of the individual rooms in the matrices, since this presentation is mainly about the total system with its integrated components. The individual rooms in the House of Quality that are essential to further discussion of the systems (see Fig. 2) are the ones 


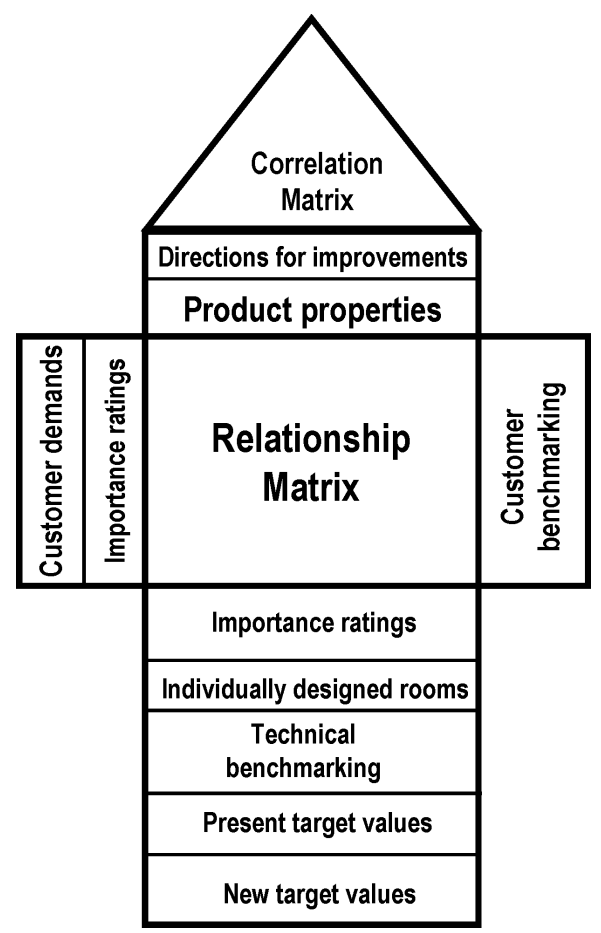

Fig. 2. "House of Quality" or the "Product Planning" matrix.

for Importance Ratings, Benchmarking, Directions for Improvements, Relationship Matrix, Correlation Matrix, and finally the room for setting Target Values.

The importance ratings of the hierarchically arranged customer demands, including the comparison with competing products in the customer dimension (customer benchmarking), are usually collectively called the "Voice of the Customer". When the Relationship Matrix is used to translate the Voice of the Customer into an engineering dimension, those measurable product properties are further developed, including the direction in which individual product properties need to be improved, and calculation of the individual importance of each product property. In the engineering dimension there is now an opportunity to run a technical benchmarking of product properties. After completion of those rooms (and possibly individually designed rooms that are applicable to a specific project), the target values for a new or improved product can be set after a thorough matrix analysis.

After the House of Quality - two alternative QFD systems and their components

Beyond the House of Quality there are two distinct QFD systems in use today. The origins of the two systems have previously been presented. The Matrix of Matrices system is the most common one in Japan and part of the United States while the Four 
Phases of Matrices system is also used in the United States and is the dominating system in Europe.

The Matrix of Matrices - a system designed by Professor Akao in Japan, and further used in the United States by GOAL/QPC

The Matrix of Matrices system can be considered as an advanced system for experienced QFD users. The original system (see Fig. 3) presented by Akao (1990), in principle, contains 16 matrices (components) and includes the four areas (columns): Quality Deployment, Technology Deployment, Cost Deployment, and Reliability Deployment. Akao recommends starting with the first column. The system is presented in a slightly different fashion by GOAL/QPC insofar as concept development is included and there are 30 matrices in the system (King, 1987). To simplify matters, the individual areas of the matrices have not been named. The number of matrices in the system may appear frightening, but we can take comfort from Akao's advice to use as many matrices as are useful for the application.

One confusing element in the use of the QFD methodology is the complexity of matrix levels for large assembled products. This is addressed well by King (1987), who illustrates the different levels of QFD applications on a car. Starting from the

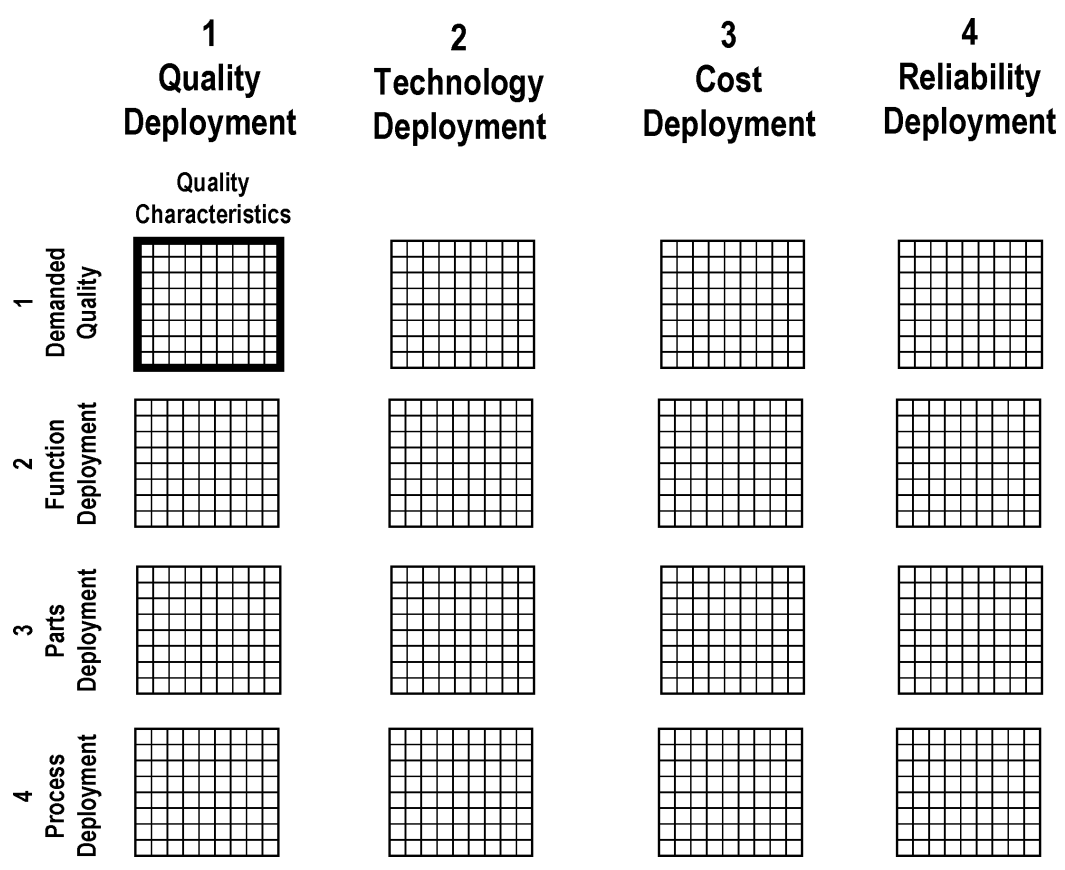

Fig. 3. The "Matrix of Matrices", a simplified presentation of the system and its components, after Akao (1990). 
highest level to the lowest level we have: product (car), system (bodywork), subsystem (door), components (door handle), parts (opening lever), raw materials (steel alloy). We will not, however, discuss this complexity further here, since this paper is about the use of the methodology in the process industry, where we have only one level in the homogeneous product. That often makes it easier to apply QFD to products from the process industry.

The Four Phases of Matrices - a system designed by Dr Fukuhara in Japan, and further used in the United States by the American Supplier Institute

Starting with the development of the House of Quality, the Customer Wants are translated into Design Requirements. These Design Requirements can serve as WHATs in a consecutive matrix to express the demands on Part Characteristics, and can then be further progressed to the Process Planning and Production Planning matrices (see Fig. 4). This is often called phase progression, and the matrices are numbered from 1 to 4 . Using the four matrices, the customer wants are thus progressed from product development and design into manufacturing. It is important to recognise that not only the individual product properties are progressed to the following matrix, but also their associated calculated importance ratings and, of utmost importance, the selected target values. Opinions differ as to how many of the product properties should be included in this progression. ASI and also Akao advocate that the properties should be subjected to a rigorous priority-ranking process to concentrate on new, important, and difficult product properties.

\section{The slightly modified Four Phases of Matrices for applications} in the process industry

The Four Phases of Matrices system was primarily developed for industries manufacturing components. Unfortunately, it is often referred to as the model for all
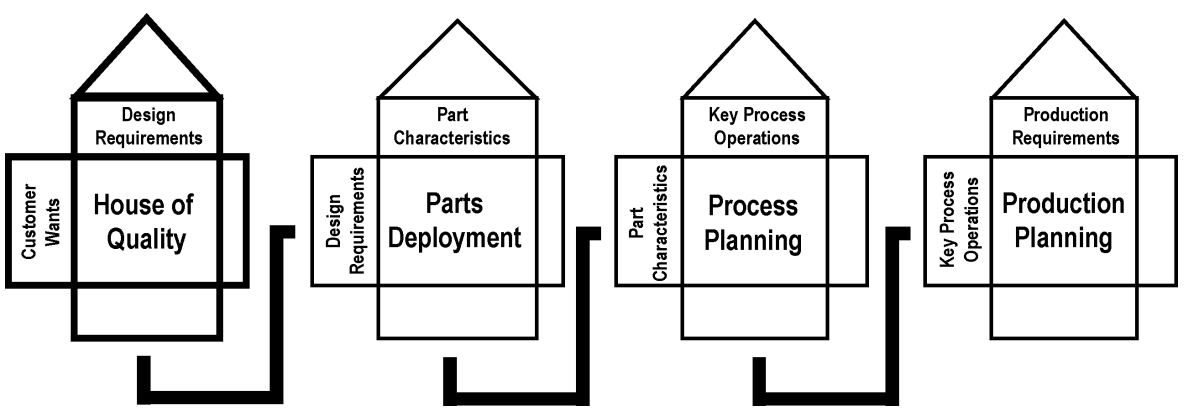

Fig. 4. The Four Phases of Matrices, a simplified presentation of the system and its components, after ASI (American Supplier Institute, 1992). 
types of industries, in spite of not being suitable for the process industry. This is, however, clearly recognised in the manuals from ASI (American Supplier Institute, 1992), where a different type of phase progression is recommended. Starting with a House of Quality, as for the other manufacturing industries, the next matrix is the Design \& Process Planning Matrix (often referred to as the phase 2/3 matrix). Since, as we have previously discussed, the products from the process industry are not an assembly of components but the transformation of raw materials or ingredients into a homogeneous product, this matrix uses the Design Requirements as WHATs but relates them to Material and Process Parameters as HOWs. It is normally recommended that the structuring of the HOWs should follow the process flowsheet. As for the last matrix, the Production Planning Matrix, the material and process parameters are related to Production Control activities and systems.

\section{A literature review of the industrial application of QFD in the process industry}

The subject of QFD methodology for applications in the process industry is sparsely and unfairly treated in reference literature. In the presentation of the Four Phases of Matrices system by Day (1993), the use of QFD for the process industry application is presented in five pages of the total book, and is mainly a reference to ASI material. In the extensive textbook on QFD by Cohen (1995), the subject is not treated at all. The best presentation of the Four Phases of Matrices system for the process industry is to be found in ASI workshop manuals (American Supplier Institute, 1989), where the methodology adapted for use in the process industry is presented on a few pages using the frequently cited case of the manufacturing of a chocolate cake. In the presentation of the Matrix of Matrices system, one interesting chapter is devoted to two cases from the process industry in the book by Akao (1990). The presentations are however of more interest to advanced users of QFD methodology than as a methodological textbook for beginners. In the early book by King (1987), presenting a slightly modified version of the Matrix of Matrices system, its use in process industry applications is not mentioned. In some other textbooks the topic is often not treated at all (Eureka and Ryan, 1988; Bossert, 1991).

Going through the QFD literature, it was noticed that there does not exist a thorough literature review in the subject area of QFD use in the process industry. The following review thus not only serves as a foundation for this study, but can also hopefully serve the purpose of a collection and reference list for QFD users in various sectors of the process industry. There are today also a number of scientific studies of the usability of QFD in general (Griffin, 1992; Vonderembse et al., 1997) that often include companies from the process industry. However, since the different results have not been related to their respective categories of industry, the conclusions are 
unfortunately not clearly applicable to the process industry. In the following review experience has been grouped into four categories of the process industry: mineral and metal industry, food and beverage industry, forest industry, and chemical and petrochemical industry.

\section{Mineral and metal industry}

The use of QFD to improve the quality of raw materials for ALCOA smelting plants is reported in an early paper by Williams (1992). The use of the methodology was focused on the importance of improvements and did not develop a classical total hierarchic structure of customer demands. One can observe that the customer is an internal customer and also far removed from the ultimate end user of alumina products. It is reported that deeper levels of QFD matrices are being used, but they are not presented.

Some methodological issues are discussed in a paper by Tottie and Lager (1995) presenting the use of QFD in the development of advanced iron ore pellets for the steel industry. In the process of listening to the customer it is important to recognise that although interviews were conducted with purchasers, blast furnace managers, logistics managers and process engineers, they only try to interpret the voice of the real customer, which is the blast furnace process itself. The engineers, with their expert knowledge, tend to express their demands in measurable technical properties of the product, a voice that cannot be ignored. One important benefit of the House of Quality is reported to be that it helps to get away from single-parameter thinking. The use of QFD for ceramic bricks is briefly presented by Pertl (1992), but the presentation is more about other quality tools, though a simplified House of Quality is shown. A rather simplistic picture of the use of QFD, also in the ceramic industry, is given by Corma (1993).

The use of QFD at Bethlehem Steel Corporation is presented in an internal periodical publication by Mongeon (1996). The methodology is generally perceived to be a powerful development tool, but experience suggests that more emphasis should be placed on its use in the production process. Several successful projects have been reported, and the conclusion is that it can be of great assistance in the development and startup of new production processes. Use of QFD in the Brazilian Belgo-Mineira Steel Company is reported by de Oliveira et al. (1996). The Akao system is used here for a change, and the results from the QFD exercise are reported to be very rewarding. The project, related to the development of rods and bars for car suspension springs, included not only the development of a House of Quality but also related separate raw material and process matrices and a complementary matrix for "Metallographic Structure". It is stated that "In the steel industry, the product concept is almost closed (compared with manufactured products where 
different parts can perform the same function), so the opportunities to balance cost and quality come only from the choice of alternative process paths, raw materials and the method of production".

Use of QFD in alumina extrusion at Westinghouse Electric Corporation is presented by Calo and Kramer (1992, p. 4): "The efforts centered about a team including commodity customer, extrusion press supplier and extrusion die fabricator sub-supplier which represented a mix of speciality engineering expertise in performance/process modeling, extrusion press practices and die fabrication.... Relationships between customer requirements and product specifications identified the key specifications and led to the development of separate matrices for die design and press practices".

\section{Food and beverage industry}

Some papers about QFD in the food industry (Duxbury, 1991; Hofmeister, 1991; Charteris, 1993) were published at the beginning of the 1990s. The first paper simply points out the possible advantages that could be obtained with QFD in a fairly superficial manner. The second book chapter by Hofmeister presents only the ASI methodology including artificial simple examples. The paper by Charteris presents a vast number of complementary methodologies and statistical tools, and mentions very briefly that the author participated in a QFD project on a dairy product with favourable results.

Both of the last-named articles take up the issue of deploying QFD on the associated package, but do not bring any original methodological ideas forward. In two papers, Bech et al. $(1995,1997)$ present the use of QFD on two food products, farmed smoked eel and frozen green peas. These papers present a somewhat unorthodox use of QFD, and one could question whether their "House of Quality" should be called QFD, as it features unconventional symbols and negative relations in the relationship matrix. The use of complementary methodologies like experimental design and sophisticated statistical analysis nevertheless makes them interesting reading. Finally, two papers present the use of QFD in the chocolate industry and in the meat industry (Guedes et al., 1999; Viaene and Januszewska, 1999).

\section{Forest industry}

There are four articles dating from the early 1990s dealing with use of QFD in forest industry applications. One article describes the introduction and use of QFD at Weyerhaeuser Company on "oriented strand board" (Hanson, 1993), and the other three cover various applications in the Kimberly-Clark Corporation (Scheurell, 1992, 1993; Stitt and York, 1993). The first paper by Hanson makes very rewarding reading, not so much about the matrices as such but the use of the methodology 
in three successful applications. As such it stresses the need for proper training in QFD, the identification of different customer groups, the need to focus on the end user, the importance of distinguishing demands on the product from demands on service and the development of more customer-oriented test methods. The intention was to progress further with deeper levels of matrices.

The two papers presented by Scheurell are a presentation of the use of QFD in a startup of a new product, using new technology and process, building a new mill with new equipment and training new operators (Scheurell, 1992). The first paper captures the team-building, objectives and industrial reality extremely well, to such an extent that it could well be used in training. The feeling of the team that the House of Quality was not being fully utilized encouraged them to develop a number of phase $2 / 3$ matrices and complementary No. 4 matrices. They came to the philosophical conclusion that QFD is not the matrices, but what you do with them. The followup paper (Scheurell, 1993) presents the results from the startup of the new mills. One important result is that if you include startup problems in the definition of the product development cycle, using the deeper levels of matrices in QFD, there can be a substantial improvement in time-to-market. Deploying the deeper levels of matrices makes QFD meet Statistical Process Control (SPC) in a natural way that is meaningful to operators. Which are the product specifications to control? Scheurell presents the very successful project results including the performance of the product on the market.

The paper by Stitt and York (1993) describes experience of using QFD to develop an improved, customer-preferred product using existing processes in an established facility. In spite of previous marginally successful QFD projects at the mill, the paper presents the successful use of QFD by further developing the phase $2 / 3$ and 4 matrices. The importance of the process control part in matrix 4 is stressed, as well as the usefulness of QFD in bridging organisational and plant interfaces. Stitt and York conclude that QFD can be used in many applications such as new products and processes, new products with existing processes, product and process improvements and cost reduction programmes, to name a few.

\section{Chemical and petrochemical industry}

In the book by Akao (1990), the usability of QFD in the process industry applications is given one chapter and the specific problems are well covered and illustrated by two industrial cases. The first case presented by Oyaizu (1990) concerns production of synthetic rubber at Nippon Zeon Company. In the introduction Oyaizu recognises the difference between the process industry and other manufacturing industries insofar as "in machine and assembly industries a demanded quality for a total system can be deployed into successively smaller subsystems. ... In process industries, however, 
a mechanism that is necessary to realize some demanded quality cannot function independently of other necessary mechanisms and functions". And further "The raw material by itself does not have full function; it is only an intermediate product in a process that will eventually allow the material to exhibit its function". The need to develop a complementary matrix to relate quality characteristics further to underlying structural properties is recognized, and the corresponding matrix is called "mechanism deployment". The second case presented by Kubota (1990) refers to the use of QFD at Nippon Carbon. The use of QFD is specially highlighted as part of the overall quality system, but it is recognised that in long production chains there are intermediate products whose properties must be related to process parameters for a full process understanding.

In a later paper by Oyaizu (1994), he discusses the problem of capturing the latent needs of the customers for new materials and developing them to manifested needs. This theme is further elaborated in a later publication (Ootakiet al., 1996). McLaughlin and Stratman (1997) propose using the S-curve concept together with QFD. The QFD methodology is presented and exemplified with a case from the chemical industry. The use of QFD, not only to translate customer demands into product attributes but to relate those attributes to process capabilities, is strongly recommended. The progression of data into deeper levels with QFD matrices is recommended in combination with analysis of technology by the S-curve methodology .

\section{An Assessment of the Usability of Present QFD Systems in the Process Industry}

The foregoing presentation of the methodological state-of-the-art and the review of published literature on the industrial applications of QFD in the process industry gave a good platform for an analysis of the needs from the process industry and what present QFD systems are able to provide.

The system should be able to cope with the long and often complex production chain of multiple customers and suppliers. Suppliers and customers are sometimes located in the middle of this chain with no direct contact with the end user.

Referring to Fig. 1, one could wonder who really is the end user in this production chain? Strictly speaking, the end user should be the customer who finds satisfaction in buying a car from Volvo. Consequently, the House of Quality should then be the concern of Volvo and not of the previous suppliers in the production chain, who according to this cannot build a House of Quality of their own. If, on the other hand, one regards sheet steel as a component (it is not changed structurally but only formed), the end user of the steel is Volvo, who is not a private customer but an 
industrial customer in the long chain of business-to-business relations. Sometimes the question is raised of whether QFD is usable at all in the process industry, since the end user sometimes is so far removed from the material producers in the long supply chain.

One approach to this problem is to see each company as both a supplier and a customer in this chain. The user demands on the functionality of the supplier's product in the customers' production environment are translated in the supplier's House of Quality into measurable product specifications. This approach gives a development perspective for the supplier in his desire to dig deeper and understand the causes of the product specifications from the customer and user of his product. The alternative approach is to regard all companies, except the supplier to the end user, simply as parts of the long complex production chain and look upon the product specifications (hopefully reflecting the demands from the customer) as product characteristics to be progressed backwards as far as possible in the chain of customers and suppliers. The lack of system $\rightarrow$ component $\rightarrow$ part hierarchical levels (e.g., car $\rightarrow$ door $\rightarrow$ door handle) in the product itself makes the development of a House of Quality easier for the kind of homogeneous product produced in the process industry. On the other hand, the aforementioned long complex production process put more demands on the development of deeper underlying matrix levels in the production system. There is strong evidence from the literature review to support the importance of going beyond the House of Quality. Present QFD systems do not however address this problem or the need for multiple chains of customer and suppliers. A new system should be able to cope with both approaches presented above, at the discretion of the user.

The system must be adapted to the types of products that are manufactured in the process industry. These are not assembled components, but homogeneous products.

Since the products from the process industry are not assembled components, there is no need for a multi-level QFD system (see previous section). The original Four Phases of Matrices system is thus not applicable, since after the product we do not have parts but the long production process, often with raw materials from another supplier. The homogeneity of the products also relates differently to the given recommendation to progress only those characteristics that are new, important or difficult to the deeper QFD levels. First of all it is perceived that it is good to progress all product properties, since one can argue that it is important to know also what is not important when cutting costs. Secondly, one product property in a homogeneous product can seldom be changed without affecting the other product properties, unlike parts in assembled products (Oyaizu, 1994). Consequently, there is a need for a QFD system that can handle multiple product characteristics well, not 
only focusing on the product but also connected to the production system. With the present system, the user tends to get bogged down in unmanageably large matrices.

The components (matrices) beyond the House of Quality must be well adapted to the production environment for the process industry. This includes production of intermediate products within the process, the influence of design parameters on product properties and the inherent demands from the production process on incoming raw materials (processability).

Not only does the production process in the process industry (see Fig. 1) have customer-supplier interfaces on a company level, but the company processes are often a long consecutive chain of internally produced intermediate products. The QFD system must be able to handle this complexity, since the intermediate products are often measured by a number of more or less sophisticated test methods (Kubota, 1990). Another matter is that it is not only the finished product that makes demands on the production process. The process takes the liberty of making its own demands on the raw materials going into it, demands we can call "processability demands". But since those demands only make sense in relation to raw materials, this gives an incentive to split process parameters and raw material properties into two matrices.

Another factor that supports this idea is that the demands on raw material can be progressed in an infinite chain from the supplier to the end user and back to the raw material that Nature provides. This is not possible with the process parameters. A split-up of process and raw material parameters will also make the individual matrices smaller and easier to handle (one problem that has often been reported in the literature).

The really convincing results from the forest industry with regard to using the control matrices suggest that these must be included in the system (Stitt and York, 1993). Because they do not constitute a system or overall model for process control, it should be possible to let them be integrated into the process matrices, not giving the misleading idea that you are developing a control model with the QFD tool. The needs from the process industry presented above are not at all addressed in the Four Phases of Matrices system. The use of separate process and raw material matrices is not formally presented in the Matrix of Matrices system, but industrial users of this system have nevertheless utilised this possibility (de Oliveira et al., 1996).

The system must pay more attention to product and process development work processes, and especially to development of new product and process concepts.

There is often a misconception, even among product developers in industry embarking on their first QFD project, that when the House of Quality has been 
built, a new product has been created. Unfortunately, this is not the case, since we have still only come to the start of the development work. Only now can the creative development work start to meet the objectives and target values. The original Matrix of Matrices system did not make allowance for the development and selection of new product concepts, but concept development is added in the slightly modified version by King (1987). This problem is even more pronounced in the Four Phases of Matrices system, and the lack of a development phase or concept development in the matrix flight of stairs gives the false impression that you only have to press the button for the development of the four consecutive matrices, and out comes a new product.

Although products from the process industry appear superficially homogeneous, there are different degrees of homogeneity in different types of products, as has been previously discussed. The understanding of other explanatory measurables and the inner structural properties' relationship to measurable product properties is of utmost importance to the product developer, but often not to the customer. The complementary matrices developed using a modified Matrix of Matrices system give good information about products from the process industry that are structurally complex (Oyaizu, 1990). This is also evident from the papers from the food industry, where sensory properties of interest to the customer are related to the substances that create them (of lesser interest to the customer's perception of taste). Concept development is not present in the original Matrix of Matrices system or in the modified ASI Four Phases of Matrices system. The use of a complementary product matrix is not formally introduced in any system.

The overall conclusion from the previous sections is thus that the specific needs of Process Industry not are particularly well addressed in today's formally presented QFD systems. The present two systems do have different individual advantages when used in other manufacturing industry, but it is generally perceived that there is a need for a QFD system specially adapted for use in the process industry.

\section{Theoretical Development of a New QFD System Specially Adapted for Use in the Process Industry}

\section{Development approach}

The development of the new system was guided by the various aspects and conclusions that were presented in the previous section. The ambition is to construct a flexible system that could be used by the advanced practitioner as well as by the beginner. The system is intended to give a structural system guidance and is not intended to be used as a "cookbook" to be followed strictly. Since studies of company experience with QFD methodology show that one of the most important 
aspects is organisational learning (Cristiano et al., 2000), the matrices (components) of the new system have been given complementary names that support this ambition. Starting with the House of Quality, a matrix (component) common to all systems for translating customer demands into measurable product properties, this matrix has been given the complementary designation "Customer Understanding". The product properties in this matrix, and their associated weights and target values, are then further progressed into the production system (the demands made by the product on the production process). The related process and raw material parameters in the production process have been split up into two categories and associated matrices. In Process Matrix 2, the product properties are related to process and design parameters, and the matrix is thus designated "Process Understanding". In Product Matrix 2A, the same product properties are related to raw material properties and the matrix is designated "Raw Material Understanding". This split of process and raw material parameters facilitates the construction and use of the matrices, enabling a multiple progression of raw material properties into deeper levels of the production system. A complementary matrix is introduced, Product Matrix 1B, facilitating a deeper understanding of the relationship between product properties and underlying and causally related explanatory physical and chemical properties of the product. This matrix has thus been designated "Product Understanding". The individual matrices (components) in the new system will be further discussed in detail in the following sections, but for a first impression of the total system structure and the individual matrices see Fig. 5.

\section{Development of the first level of the system}

If a company decides to use the QFD methodology, it is always started by building a House of Quality. And this is the first matrix to start with in the new system too.

\section{Customer Understanding}

The first matrix (component) in the new system has the complementary designation Customer Understanding because the primary object of this matrix is to translate customer demands (WHATs) on the product further into a company engineering dimension and measurable product properties (HOWs). All the rooms that have been conventionally used in a House of Quality in other systems can also be used in this matrix (see Fig. 2). Figure 5 shows only some of the rooms from Fig. 2 where the importance ratings from the individual and hierarchically arranged customer demands are recalculated into importance ratings for individual product properties, using the relationship matrix. New or modified target values are set (new product specifications) to be met in further product development. If the company does not sell its product to an end user but is located within the aforementioned long chain 

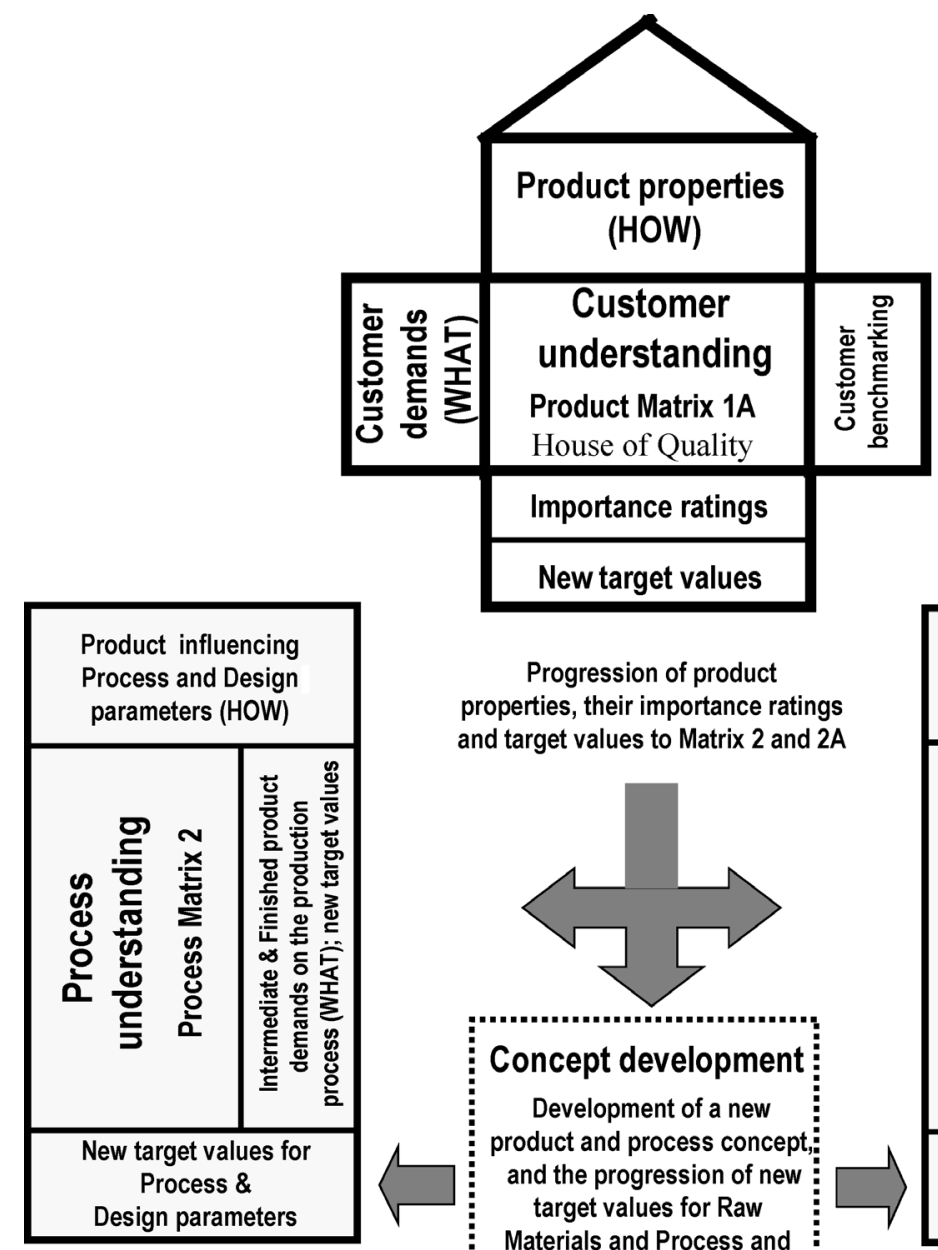

Progression of product properties, their importance ratings and target values to Matrix 2 and 2A
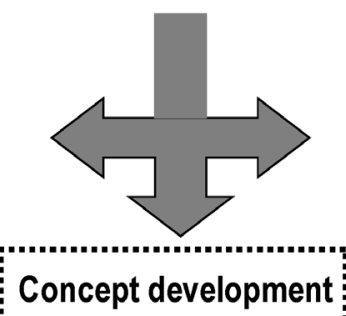

Development of a new product and process concept, and the progression of new target values for Raw Materials and Process and Design parameters

Explanatory product information for development work

\begin{tabular}{|c|c|}
\hline 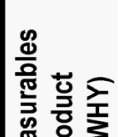 & $\begin{array}{c}\text { Selected product properties from } \\
\text { Matrix } 1 \mathrm{~A} \text { and complementary } \\
\text { new measurables of customer } \\
\text { demands (HOW) }\end{array}$ \\
\hline 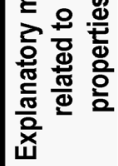 & $\begin{array}{l}\text { Product } \\
\text { understanding } \\
\text { Product Matrix 1B }\end{array}$ \\
\hline
\end{tabular}

Product and process influencing Raw Material properties (HOW)
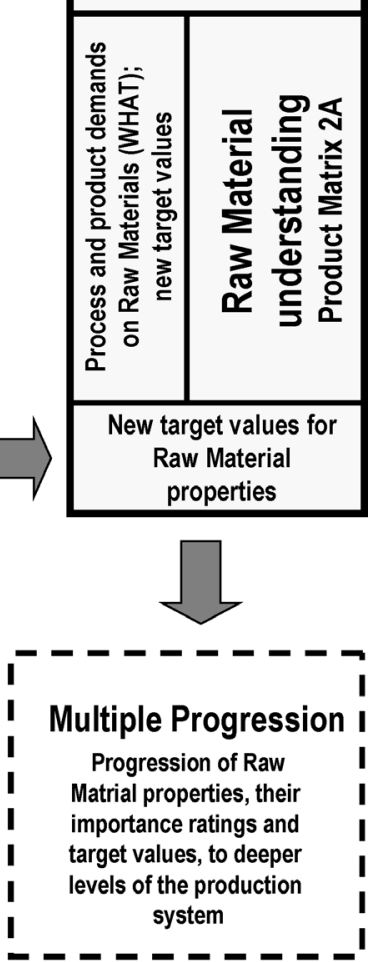

Fig. 5. The simplified structure of the proposed new QFD system; the total system and its individual matrices (components). Starting with the House of Quality, a number of matrices can be separately selected in the further progression, or alternatively all four of them. The large squares with solid outlines are the four matrices (components) in the system, while the dotted square indicates concept development. The "Multiple Progression" of raw material properties can now be carried out in an infinite chain backwards in the production process, using only the Product Matrices. 
of customers and suppliers, one approach is to disregard the development of the WHATs of the matrix and let the measurable individual product properties (HOWs) and their associated importance ratings and target values (sometimes jointly set by the supplier and customer) be regarded as the starting point for the development of underlying process and raw material matrices for the product. With this approach the House of Quality is disregarded and the product specifications are directly used as the WHATs in the underlying Product Matrix 2A and Process Matrix 2. The alternative approach is however to ask the customer to explain why he or she requires those particular product specifications and how they relate to the customer's functional use of the product. With this approach, a deeper understanding of the customer's need is achieved. In other words, one can say that an interacting product specification is developed that makes the selected product specifications traceable backwards to the customer's functional use of the product and an improved Customer Understanding is achieved. In summary, each QFD user within the long production chain can decide to start only with measurable product properties or to develop a full House of Quality, much depending on whether the company is planning to develop the product further or whether it simply wants to progress the product specifications as the customer's demands into the production process.

\section{Process and raw material understanding}

When the individual product properties and their associated importance ratings and target values are progressed into the production process, they can be related to process parameters and raw material properties. Since process parameters, unlike raw material properties, cannot be progressed into deeper levels of the production process, and because "processability" can pose demands on the raw materials but not on process parameters, they have been split into two separate matrices in the new system.

In Fig. 5, intermediate and finished product demands (WHATs for Process Matrix 2) are thus related to product-influencing process and design parameters. The finished product demands are the ones that have been progressed from the previously presented product properties in the House of Quality. When the process is a large chain of interrelated sub-processes, and it has been decided to treat the overall process as one part, there are often intermediate products in the process chain that are measured and used in the process control system. Neglecting them in Process Matrix 2 seriously hampers the usability of the matrix. These demands on the process can be related to product-influencing process and design parameters in the relationship matrix of Process Matrix 2. Those process parameters should be selected which, if changed, will influence product properties. It is suggested that the design parameters should be omitted if only minor product improvements are 
under consideration, to make the matrix smaller and easier to handle. If however a completely new product is being developed, design parameters should be included, but only those that have a control span and a pronounced impact on product properties. All other conventional rooms in a QFD matrix could also be utilised, but are not explicitly shown. In this system, the recommendation is to include the related process control rooms directly under the relationship matrix related to the HOWs of Process Matrix 2 to simplify the number of necessary matrices. The use of this matrix relates product properties and intermediate product properties to controlling process parameters, and thus improves Process Understanding.

In Fig. 5, process and product demands (WHATs for Product Matrix 2A) are related to raw material properties. The finished product demands are the ones that have been progressed from the previously presented product properties in the House of Quality. The process demands are the inherent demands the production process makes on raw material properties. These demands are not derived from the House of Quality, but are collected from within the company's own production organisation, and are designated "processability" demands. Processability demands can include demands on material handling properties as well as those related to ease of processing. The importance ratings of processability demands cannot be derived from the House of Quality, but must be developed by the production organisation. The characteristics of measurable raw material properties must be developed by judging the influence on finished product or processability. Those properties are often the specifications that are given to the purchasing organisation to be negotiated with raw material suppliers. The development of the relationship matrix is similar to Process Matrix 2, and the same goes for all associated complementary rooms within the matrix. Depending on the complexity of the raw materials, each of them may sometimes need a separate matrix. The use of this matrix focuses on raw material properties that either influence the finished product properties or the "processability" of raw materials, thus creating a better Raw Material Understanding.

\section{Product Understanding}

An enhanced Product Understanding can be obtained through the development of the complementary Product Matrix 1B for complex or structurally designed products. In Fig. 5, selected product properties from the House of Quality (HOWs) and newly developed measurables of previously unmeasured customer demands are progressed into Product Matrix 1B, relating them to the products' inner (structural) product properties or other explanatory measurables, called WHYs.

When the WHATs in the previously presented House of Quality are reviewed, and if there is a need to develop new or more sophisticated measurement methods and techniques that capture those customer needs, those complementary HOWs 
should be included in this matrix. The importance ratings for those newly developed HOWs can be calculated using a complementary relationship matrix, part of the House of Quality. If there are product properties that are not measured on a continuous basis in the production process (or if they are of a research character), this is the matrix where they should be introduced. This complementary matrix may be utilised where a completely new product is being developed, or if one is seeking an improved understanding of what deeper underlying mechanisms create the measurable properties of the product. The measurable properties of the final products, and to some extent the necessary process conditions that produce these properties, are often well known. But what causes those properties, for example, the deeper structural product properties, are often difficult to measure and sometimes difficult to understand, and are less well known. The more structurally heterogeneous the product is, the greater the need for this complementary Product Matrix 1B as an aid to designing the product concept. Use of this matrix can explain why a product acquires certain measurable properties, and thus gives a deeper and more intimate Product Understanding.

\section{Concept Development}

The previously presented matrices give a large amount of information for the product development process. The House of Quality utilises a deeper understanding of the customer demands and translates them into measurable product specifications that make up some sort of "target value screen" through which new or improved product concepts can be sifted. The product properties of new product concepts are measured and tested with this screen to determine whether they comply with the new target values set up for the new product. Not only must new product concepts be developed, but related process concepts must simultaneously be developed for the future production process of the new product. When a new or improved product concept has thus been developed, new target values can be set for the production process and progressed further into Process Matrix 2 and Product Matrix 2A. The concept development is the result of product and process development activities and is one major activity in a product development project. The QFD system should give a structural backbone for development, more specifically concept development, which is further illustrated in Fig. 5. Different product concepts can be evaluated with techniques such as the concept selection methodology developed by Pugh (1981).

\section{Linking the parts together and creating the first level of the system}

The four matrices (components) of the system have now been presented, including the activity of concept development; the first system level is now completed and 
assembled in Fig. 5. Starting from the House of Quality at the top of Fig. 5, the product properties, importance ratings and target values are progressed into the production system that is represented by the Process and Raw Material matrices. These progressed properties form part of the demands on process parameters and raw material properties. After the development of those relationship matrices, new target values arising from new product and process concepts can also be progressed into those matrices. The complementary Product Matrix 1B is shown in the bottom left-hand corner of the figure.

\section{Development of deeper levels of the system - "Multiple Progression"}

The square with the broken outline in the bottom right-hand corner of Fig. 5 indicates that with this new system there is an option to progress raw material properties and their associated calculated importance ratings and new target values into deeper levels of the production system.

Referring to the complex production chain in Fig. 1, the measurable raw material properties that are expressed in Product Matrix 2A can be further progressed backwards into deeper levels of this production chain. The (internal or external) suppliers of raw materials can look upon these as the HOWs of their own House of Quality. Using the system that is presented in Fig. 5, those HOWs (measurable raw material properties, importance ratings and associated target values) can be progressed into the supplier's own production process, where matrices of a similar kind can be developed. The raw material properties, importance ratings and new target values from the supplier's matrix, designated Product Matrix 3A, can be cascaded further into even deeper levels of the production system until they become the specifications for raw materials that are available as "in situ natural resources".

The raw-material supplier to the customer not only has the option to develop a Product Matrix 3A but can also develop a process matrix, designated Process Matrix 3. A complementary product matrix for explanatory product understanding, designated Product Matrix 2B, can also be developed to yield new product and process concepts.

The numbering and designations of the individual matrices in the previous presentation may have been confusing, but the explanation had to wait for the total system to be presented. If the development of a House of Quality starts with the customer as the end user, the matrix is designated Product Matrix 1A. The complementary explanatory matrix is then consequently called Product Matrix 1B. After a progression of measurable product properties into the production system, the new matrix on this production level is consequently called Product Matrix 2A. The adjacent process matrix is then called Process Matrix 2. The finished product matrix related to the end user are thus given the number one, and the following associated 
production level number two. If the chain of progression continues further into the production system, the new production level is called three; here the raw material matrix is called Product Matrix 3A, and so on. If the QFD system starts in the middle of the production chain, the first House of Quality can be designated by any number as long as the cascaded new matrices follow the system presented above. If one matrix is developed for each raw material on production level two, the data from each of them can be cascaded into the individual underlying production systems. There are several new characteristics included in the proposed new system, but one of the main differences from the present systems is the ability to make a multiple progression of product properties backwards into the often long production chain. The new system has consequently been designated "Multiple Progression".

\section{An Explanatory Case of Industrial Beer Manufacturing}

Methodologies, and QFD methodology in particular, tend to be rather difficult to comprehend using only theoretical descriptions and models. The understanding of complicated methodological issues thus often benefits from simplified or artificial examples (QFD on a mousetrap) or instructive real cases from industry. Since the proposed new QFD system has not been used so far in a completed real industrial case, part of an old real industrial QFD project has been selected and transformed into the new system structure to illustrate the main principles of the new QFD system. The case has been greatly simplified, slightly modified in structure and supplemented with new data and matrices. The case selected from the process industry refers to the industrial manufacturing of a beer, specifically the manufacturing of "a good beer for lunch", see Fig. 6.

The large hierarchic structures of WHATs and HOWs have been omitted, and only a few of the "root" demands and properties have been included. The original importance ratings of consumer demands and benchmarking in the "House of Quality" used a nine-point scale. The symbols in the relationship matrices are the conventional ones indicating different strengths in the relation. A strong relation (weight 9) is marked by a double ring, a medium relation (weight 3) by a ring and finally a weak relation (weight 1 ) by a triangle. The product properties from the House of Quality are progressed together with their individual importance ratings into the consecutive matrices, where the importance ratings of the HOWs are calculated by multiplication and an accumulative summary. The direction a single and isolated product property should follow to please the customer is indicated by arrows (up for increased intensity, down for decreased intensity and a ring for nominal intensity).

In the House of Quality the WHATs on the left of the matrix are: good head, smells good, well balanced and easy to drink. The importance ratings by consumers 

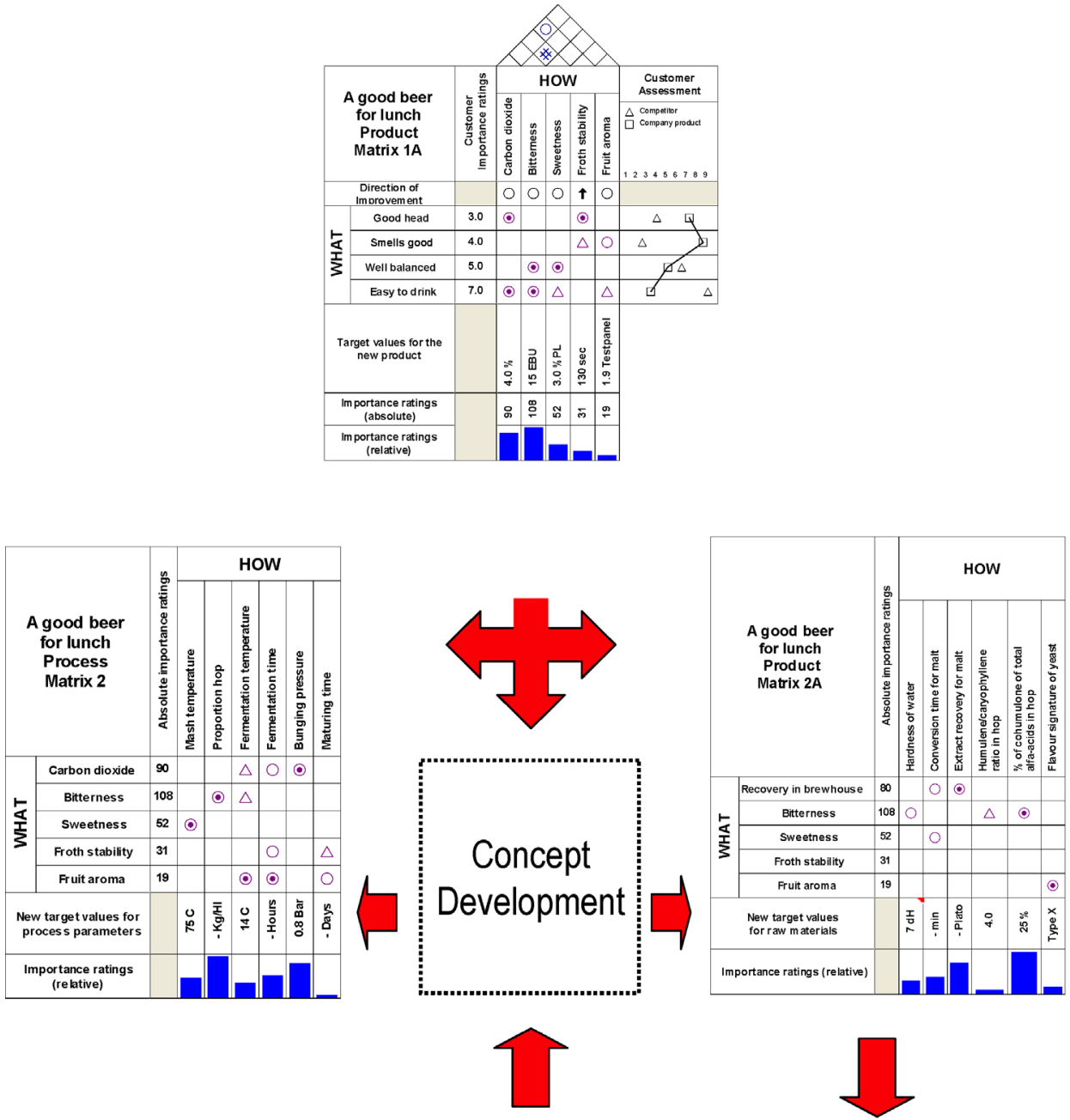

\begin{tabular}{|c|c|c|c|c|c|c|c|}
\hline & & & & & $\mathrm{HC}$ & W & \\
\hline & $\begin{array}{l}\text { ood beer for lunch } \\
\text { roduct Matrix 1B }\end{array}$ & 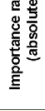 & 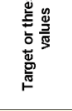 & 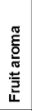 & 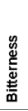 & $\begin{array}{l}\text { 怘 } \\
\text { 竧 } \\
\text { 岁 } \\
\text { 心 }\end{array}$ & 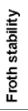 \\
\hline & solute importance ratings & & & $\stackrel{9}{2}$ & $\stackrel{\infty}{\stackrel{0}{0}}$ & 땡 & A \\
\hline & Isohumulone content & 972 & $25 \%$ & & () & & \\
\hline & Fructose content & 175 & & $\Delta$ & & 0 & \\
\hline & S-methyl methionine (SMM) & 19 & & $\Delta$ & & & \\
\hline$\sum^{T}$ & Glycoprotein content & 279 & & & & & $\odot$ \\
\hline & Propanol (fusel alcohol) & 71 & $600 \mathrm{mg} / \mathrm{L}$ & $\triangle$ & & $\Delta$ & \\
\hline & Ehyl acetate (ester) & 57 & $50 \mathrm{mg} / \mathrm{L}$ & 0 & & & \\
\hline & Acetoin (ketone) & 0 & $20 \mathrm{mg} / \mathrm{L}$ & $\Delta$ & & & \\
\hline
\end{tabular}

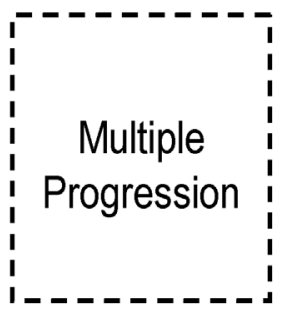

Fig. 6. A good beer for lunch. Product Matrix 1A (House of Quality) and Product Matrix 1B for a beer. Progression of product properties, importance ratings and target values to Process Matrix 2 and Product Matrix 2A. A QFD program from IDEACore has been used (IDEACore, 2003). 
are given for each of these demands, and the company product is benchmarked on the right side of the relationship matrix. These three rooms make up what is usually called the "Voice of the Customer". Unfortunately, it turns out that the company's own product excels in areas that are not so important, while the competitor is exceptionally strong in the most important areas.

Some selected measurable properties of a beer that relate to these consumer demands are presented as the HOWs in the matrix: carbon dioxide, bitterness, sweetness, froth stability and fruit aroma. The absolute and relative importance ratings for the HOWs have been calculated using the strength of individual relations marked by the symbols. After an analysis of this matrix (which is not further discussed), new target values for an improved product have been set. The product properties, their importance ratings and selected new target values can now be progressed further into the production process.

The selected measurables of the beer (carbon dioxide content has been omitted for reasons of simplification) form part of the WHATs in Product Matrix 2A. The new demand that has been added to the WHATs, "recovery in the brewhouse", is to illustrate the development of the group of demands that is called "processability". A set of selected raw material properties that influence the product properties are developed and presented as the HOWs in this matrix: hardness of water, conversion time for malt, extract recovery for malt, humulene/caryophyllene ratio in hop, $\%$ of cohumulone of total alfa-acids in hop and finally flavour signature of yeast.

The importance ratings of the raw material properties have been calculated using the relationship matrix that has been developed. For example, one can notice that the raw material that has the strongest relation to the most important product property, bitterness, is the cohumulone content in hop, which gives this the highest relative importance of all raw material properties. Process Matrix 2 has been developed in a similar fashion.

To improve Product Understanding, the measurable product properties from the House of Quality are further progressed into Product Matrix 1B, presented at the bottom of Fig. 6. Those selected HOWs are then related to underlying chemical or physical properties that can be detected or measured with more sophisticated measurements in a beer. To exemplify this, the product property stable froth, measured by the froth stability test method, does not explain the underlying mechanisms in a beer that create a stable froth. The related mechanisms (WHYs) in this case are, among other things, the glycoprotein content.

In the development process of improving the beer, some new product and related process concepts are developed. The information from Product Matrix 1B, which is primarily a tool for the developers and not the brewmaster, assists in this creative work. When a product concept is selected that has been screened through the target values of the HOWs in the House of Quality, target values for the new process 
concept and raw-material properties can be progressed into Process Matrix 2 and Product Matrix 2A. The new target value for $\%$ cohumulone in hop is, for example, set at $25 \%$. To make the improved product, not only must the target values for the process be kept, but the required raw material properties of hop, for example, must be progressed further to the (internal or external) supplier of hop, who in his turn must consider his own process for his hop product. This cascading of raw material properties is what has been called Multiple Progression.

\section{Implications for Industry and Academic Research}

Improving the usability of methodologies is an important task for academic research. Industry representatives are mainly users of methodologies, but are also important application developers insofar as they search for new areas to use methodologies. Academics often study industrial usability, hopefully in a proper scientific manner, through individual case studies or surveys. The author is thus of the opinion that responsibility for improving methodology rests mainly on the shoulders of academic researchers.

The only criteria of whether a methodology is usable by and beneficial to industry are the results that are achieved in its industrial application. The intention behind the development of this new QFD system is thus that it shall be used in new QFD projects in the process industry, hopefully leading to improved development results. In the use of QFD methodologies, the author shares the pragmatic approach advocated by Professor Akao:

"Generally speaking, the best method is not to play it by the book. Since each company's conditions are unique, it is important to be imaginative in applying the rules and to find a method that is suitable to your company" (Akao, 1990, p. 3).

The system presented here is thus intended to provide a theoretical backbone and structure that can be used in its entirety or in its individual parts at the discretion of the user. This new system is however designed to fit the needs of users who operate in only one part of the long chain of customer and suppliers in the process industry, and who consequently do not have access to the demands and needs of the final user of a product or system. The individual rooms in the matrices are not dealt with in detail in this paper; the user should use the rooms he finds interesting, and is encouraged to develop new types of rooms according to his own needs.

The industrial need for this system and its usability in the process industry will be determined in future industrial development projects. Since reporting the results from the use of methodologies takes a lot of effort, there is a mission for academic researchers to report on this and to suggest methodology improvements if necessary. 
The author welcomes this type of information, and urges that the feasibility of the new system should be tested in demanding industrial applications. The ultimate criterion of scientific propositions or hypotheses is that they must be testable. In the light of this, the new system can be looked upon as a series of testable propositions when the question is put: "How usable are the total system, its individual components and its rooms?"

\section{Conclusions}

The review of current literature on QFD methodology and on the use of QFD in the process industry reveals that there are methodological issues in the application of QFD in the process industry that are not properly addressed by the two present QFD systems. Using this information, and supported by the author's own knowledge of the needs for product and process development in the process industry, a theoretical structure of a new QFD system, especially adapted for use in the process industry, has been developed. The proposed new QFD system is, among other things, designed to be an efficient vehicle for organisational learning, and the matrices have consequently been given explanatory secondary names to emphasise this role in the development process. It is also hoped that the review of the QFD methodology for the process industry can in itself be helpful to potential new users of QFD in the process industry.

In view of the interesting results from going beyond the House of Quality, reported by previous users of QFD in the process industry, it is hoped that the proposed new system will encourage and facilitate this so that industry professionals can reap the potential benefits of the QFD methodology. In the new system, demands on product properties can thus be progressed in an infinite chain, back to raw material properties in situ. The overall system, consequently called Multiple Progression, is not only intended for use in product and process development work, but also for the progression of product and quality specifications in production control.

The new system has been "pilot tested" on professionals in the process industry with strong QFD experience, and it has recently been used for the first time in a large full-scale QFD project in a Swedish company in the process industry with excellent results.

\section{Acknowledgements}

Apart from giving important comments during the development of the new QFD system, Robert Svanberg (Arlafoods) has given invaluable assistance using his previous industrial experience in the art of development and manufacturing of beer products. Thanks are due to Magnus Tottie (LKAB) for reviewing the manuscript and 
suggesting useful improvements. My sincere thanks to Professor Takao Fujiwara, who provided a creative climate and assistance with the translation of selected QFD articles from Japanese when I was a visiting researcher at the Toyohashi University of Technology in Japan. Thanks also to Professor Yoji Akao and Professor Kozo Koura for supplying material on QFD and arranging visits to industry. Thanks to anonymous referees. Financial support from Jan Wallander's and Tom Hedelius' research foundation is gratefully acknowledged.

\section{References}

Akao, Y (ed.) (1990). Quality Function Deployment: Integrating Customer Requirements into Product Design. Cambridge: Productivity Press.

American Supplier Institute (1989). Quality Function Deployment - Three Day Workshop. Dearborn: American Supplier Institute Inc.

American Supplier Institute (1992). QFD - Kundorienterad produktutveckling hårdvara \& process. Dearborn: American Supplier Institute Inc.

Bech, AC, M Hansen and L Wienberg (1997). Application of House of Quality in translation of consumer needs into sensory attributes measurable by descriptive sensory analyses. Food Quality and Preference, 8, 329-348.

Bech, AC, K Kristensen, HJ Juhl and CS Poulsen (1995). Development of farmed smoked eel in accordance with consumer demands. In Seafood from Producer to Consumer, Integrated Approach to Quality - Proceedings of the International Seafood Conference, JB Luten (ed.). Noordwijkerhout: Elsevier Science.

Bossert, JL (1991). Quality Function Deployment - A Practitioner's Approach, Vol. 21. Milwaukee: ASQC Quality Press.

Calo, R and S Kramer (1992). Total quality management in the tight tolerance aluminum extrusion process. In 5th International Aluminum Extrusion Technology Seminar, Vol. 1, pp. 467-483. Chicago: The Aluminum Association.

Charteris, W (1993). Quality function deployment: A quality engineering technology for food industry. Journal of the Society of Dairy Technology, 46, 12-21.

Cohen, L (1995). Quality Function Deployment - How to Make QFD Work for You. Reading, MA: Addison-Wesley Publishing Company.

Corma, F (1993). QFD in Ceramics. In Third Euro-Ceramics, Vol. 2, P Ourén and JF Fernández (eds.), pp. 1077-1082.

Cristiano, JJ, JK Liker and CC White III (2000). Customer-driven product development through quality function deployment in the U.S. and Japan. Journal of Product Innovation Management, 17, 286-308.

Day, RG (1993). Quality Function Deployment — Linking a Company with Its Customers. Milwaukee: ASQ Quality Press.

de Oliveira, CA, W Magri, IV Torres, ALM Cunha, MAM Bosco and ADA Caixeta (1996). QFD in a Brazilian steel company. In Transactions from the Eighth Symposium on Quality Function Deployment. Novi: QFD Institute. 
Duxbury, D (1991). "High Tech" QFD and TQM programs produce all-natural ingredients. Food Processing, 52, 46-48.

Eureka, WE and NE Ryan (1988). The Customer Driven Company. Dearborn: American Supplier Institute Inc.

Griffin, A (1992). Evaluating QFD's use in US firms as a process. Journal of Product Innovation Management, 9, 171-187.

Guedes, LBR, I Antoni, JC Andrade, MT Galvao, LC Olivera, P Matsunaga, R Saraiva, M Cremaschi, T Soffiatti, R Watanabe and W Santos (1999). Obtaining countrywide success through QFD implementation in the development process of a popular Brazilian food product. In Fifth International Symposium on Quality Function Deployment, pp. 66-74.

Hanson, D (1993). Quality function deployment for product and service improvement. In Transactions from the Fifth Symposium on Quality Function Deployment. Novi: QFD Institute.

Hauser, JR and D Clausing (1988). The House of Quality. Harvard Business Review, MayJune, 63-73.

Hofmeister, KR (1991). Quality function deployment: Market success through customerdriven products. Food Product Development, 189-211.

IDEACore (2003). QFD Designer. Birmingham: IDEACore.

King, B (1987). Better Design in Half the Time - Implementing QFD Quality Function Deployment in America. GOAL/QPC, Methuen.

Kubota, I (1990). Using quality function deployment: The case of Nippon-Carbon. In Quality Function Deployment Integrating Customer Requirements into Product Design, Y Akao (ed.), pp. 244-250. Cambridge: Productivity Press.

Lager, T (2000). A new conceptual model for the development of process technology in process industry. International Journal of Innovation Management, 4, 319-346.

Lager, T (2002). Product and process development intensity in process industry: A conceptual and empirical analysis of the allocation of company resources for the development of process technology. International Journal of Innovation Management, 4, 105-130.

Martins, A and EM Aspinwall (2001). Quality function deployment: An empirical study in the UK. Total Quality Management, 12, 575-588.

McLaughlin, CP and J Stratman (1997). Improving the quality of corporate technical planning: Dynamic analogues of QFD. R\&D Management, 27, 269-279.

Mongeon, DL (1996). Bethlehem Steel Experience. Bethlehem.

Neelamkavil, F (1987). Computer Simulation and Modelling. Chichester: John Wiley \& Sons.

Ootaki, A, M Oyaizu and K Koura (1996). How to connect material and technology seeds to customer needs. In Transactions from the Eighth Symposium on Quality Function Deployment. Novi: QFD Institute.

Oyaizu, M (1990). New product development using quality technology deployment: The case of Nippon Zeon. In Quality Function Deployment: Integrating Customer Requirements into Product Design, Y Akao (ed.), pp. 239-244. Cambridge: Productivity Press. 
Oyaizu, M (1994). QFD applied in the development and planning of a material producer. Hinshitsu, 24, 126-131.

Pertl, A (1992). Present day quality assurance for manufacture of refractories. In RadexRundschau, Vol. 1, pp. 3-13. Austria: Veitsch-Radex Aktiengesellschaft fur feuerfeste Erzeugnisse.

Pugh, S (1981). Concept selection - A method that works. In International Conference on Engineering Design, pp. 497-506, Rome.

Scheurell, DM (1992). Taking QFD through to the production planning matrix: Putting the customer on the line. In Transactions from the Fourth Symposium on Quality Function Deployment, pp. 532-543. Novi: QFD Institute.

Scheurell, DM (1993). Concurrent engineering and the entire QFD process: One year after start-up of a new mill. In Transactions from the Fifth Symposium on Quality Function Deployment, pp. 175-184. Novi: QFD Institute.

Stitt, J and C York (1993). Just do it. In Transactions from the Fifth Symposium on Quality Function Deployment. Novi: QFD Institute.

Tottie, M and T Lager (1995). QFD-linking the customer to the product development process as a part of the TQM concept. $R \& D$ Management, July, 257-267.

Viaene, J and R Januszewska (1999). Quality function deployment in the chocolate industry. Food Quality and Preference, 10, 377-385.

Williams, FS (1992). Improving customer/supplier relationships between alumina refining and smelting. In Light Metals, ER Cutshall (ed.), pp. 241-245. The Mineral, Metals \& Materials Society.

Vonderembse, M, T Van Fossen and TS Raghunathan (1997). Is quality function deployment good for product development? Forty companies say yes. Quality Management Journal, 4, 65-79. 
Copyright of International Journal of Innovation Management is the property of World Scientific Publishing Company. The copyright in an individual article may be maintained by the author in certain cases. Content may not be copied or emailed to multiple sites or posted to a listserv without the copyright holder's express written permission. However, users may print, download, or email articles for individual use. 